\title{
Antibiotic Resistance Patterns and Prevalence of PER and $V E B$ Resistance Genes among Clinical Isolates of ESBL-Producing Acinetobacter Baumannii
}

Hasan Vahidi Emami (MSc)

Department of Microbiology, Faculty of Basic Sciences, Qom Branch, Islamic Azad University, Qom, Iran

Mohaddeseh Khalilian (PhD)

Department of Microbiology, Faculty of Biological Sciences, Shahid Beheshti University, Tehran, Iran

Narges Yadollahi Movahhed (MSc)

Department of Microbiology, Faculty of Basic Sciences, Islamic Azad University, Qom Branch, Qom, Iran

Corresponding author: Mohaddeseh Khalilian

Email: m.khalilian88@yahoo.com Tel: +989198675822

Address: Department of

Microbiology, Faculty of Biological Sciences, Shahid Beheshti University, Tehran, Iran

Received : 24 Jun 2017

Revised: 10 Nov 2017

Accepted: 20 Nov 2017

\section{ABSTRACT}

Background and Objectives: Acinetobacter species are responsible for a wide range of clinical complications in hospitalized patients. Antimicrobial treatment of clinical strains of Acinetobacter baumannii may be compromised due to multiple-drug resistance to $\beta$-lactams. Aim of this study was to determine antibiotic resistance patterns and frequency of PER and VEB genes in A. baumannii isolates from hospitalized patients.

Methods: In this cross-sectional study, 100 clinical strains of $A$. baumannii were isolated from patients hospitalized in Qom (Iran) using specific culture media and biochemical tests. The disk diffusion method was performed to determine resistance to some antibiotics. Minimum inhibitory concentration (IIC) for cefepime and ceftazidime was evaluated. Identification of ESBL-producing strains and presence of the PER and VEB genes were determined by combined disk test and polymerase chain reaction, respectively.

Results: The isolates were highly resistant against cefixime, ceftriaxone and cefepime. Lowest level of resistance was against polymyxin B. In addition, $70 \%$ of the isolates were multi-drug resistant. MIC $<128 \mu \mathrm{g} / \mathrm{ml}$ to ceftazidime and cefepime was observed in $84 \%$ and $91 \%$ of the strains, respectively. Moreover, $21 \%$ of the strains were ESBL-positive and frequency of the PER and VEB genes was $47 \%$ and $32 \%$, respectively.

Conclusion: Majority of $A$. baumannii isolates are highly resistant to the tested antibiotics. Due to presence of the PER and VEB genes in the isolated strains, there is the possibility of resistance spread to other bacteria. Therefore, it is recommended to modify the consumption pattern for antibiotics and pay more attention to standards of nosocomial infection control.

Keywords: Acinetobacter baumannii, Drug resistance, PER, VEB. 


\section{INTRODUCTION}

Acinetobacter is a genus of Gramnegative, aerobic and non-fermentative cocobacilli. These bacteria are important opportunistic pathogens responsible for nosocomial infections. Acinetobacter baumannii is one of the main causes of hospital infections $(1,2)$. Infections caused by this bacterium could be life threatening, particularly in patients who are hospitalized in the intensive care unit of hospitals such as patients with cystic fibrosis, neutropenia, immunodeficiency (3). A. baumannii infections in hospitals frequently affects respiratory tract and can cause urinary tract infection, wound infection and septicemia (4).

A. baumannii colonization is increasing in hospitalized patients, especially in long-term hospitalized patients or those receiving extensive antimicrobial treatment or anticancer therapy $(3,5)$. In recent years, the prevalence of bacterial resistance to common antibiotics has increased worldwide. Antibiotic resistance is considered as a major problem in the treatment and control of infections (6). In addition, numerous studies have reported that the high rate of antibiotic resistance and subsequent increase in prevalence of hospital infections are due to indiscriminate use of antibiotics (7).

The high resistance of $A$. baumannii against antimicrobial agents may be intrinsic or due to genetic exchange of resistance factors. Majority of A. baumannii strains are resistant to ampicillin, amoxicillin-clavulanic acid, antistaphylococcal penicillin, expandedspectrum cephalosporins (except ceftazidime and cefepime), tetracycline, macrolides, rifampin and chloramphenicol. The resistance to non-carbapenem $\beta$-lactamases is widely accompanied by overproduction of cephalosporinases. The resistance to antimicrobial agents among clinical isolates may complicate the infection treatment process and have detrimental effects on disease outcomes and healthcare costs $(8,9)$.

Different types of $\beta$-lactamases have been identified based on their characteristics and activities (10). Extended-spectrum betalactamases (ESBLs) are a group of enzymes that are able to hydrolyze $\beta$-lactam antibiotics, including penicillin, expanded-spectrum cephalosporins, fourth-generation cephalosporins (cefepime) and aztreonam (11).
Most enzymes initially identified in 1980 were SHV and TEM. In addition to the main families, new families of ESBLs including PER, VEB, BEL, TLA, GES and BES have emerged globally (12). $\beta$-lactamase production is known as the most important cause of resistance to $\beta$-lactam antibiotics (10). In fact, the rapid transmission and dissemination of these enzymes have increased the prevalence of nosocomial infections. This study aimed at phenotypic investigation of ESBLs and molecular identification of $P E R$ and $V E B$ resistance genes in A. baumannii isolates.

\section{MATERIAL AND METHODS}

In this study, 100 clinical samples from blood, urine, skin, wound, tracheal secretion and the respiratory tract were collected from hospitals in Qom province (Iran) between 2014 and 2015. MacConkey agar and Blood agar (Merck, Germany) were used for the primary isolation of bacteria. Bacteria were identified based on morphology (colony shape and Gram-reaction) and conventional biochemical tests including TSI, urease, SIM, MR/VP, OF, oxidase, catalase and etc. (Merck, Germany) (13).

Antimicrobial susceptibility test was done on Mueller-Hinton agar (Merck, Germany) using the disc-diffusion method, according to the manufacturer's instructions and Clinical and Laboratory Standards Institute (CLSI) guidelines. Eighteen antibiotics discs (MAST Diagnostic Co., UK) were used in the study including ampicillin-sulbactam ( $\left.\mathrm{AS}_{20}\right)$, ceftriaxone $\left(\mathrm{CRO}_{30}\right)$, amikacin $\left(\mathrm{AK}_{30}\right)$, imipenem $\left(\mathrm{IPM}_{10}\right)$, cefepime $\left(\mathrm{FEP}_{30}\right)$, gentamicin $\left(\mathrm{GM}_{10}\right)$, meropenem $\left(\mathrm{MEM}_{10}\right)$, Cotrimixazole $\left(\mathrm{BA}_{25}\right)$, ciprofloxacin $\left(\mathrm{CIP}_{5}\right)$, levofloxacin $\left(\mathrm{LVX}_{5}\right)$, colisitin $\left(\mathrm{CO}_{10}\right)$, cefpodoxime $\left(\mathrm{CPD}_{10}\right)$, ceftizoxime $\left(\mathrm{CL}_{30}\right)$, cefixime $\left(\mathrm{CFM}_{5}\right)$, ticarcilin $\left(\mathrm{TC}_{75}\right)$, aztreonam $\left(\mathrm{ATM}_{30}\right)$, Ceftazidime $\left(\mathrm{CAZ}_{30}\right)$ and polymyxin B $\left(\mathrm{PB}_{300}\right)$. Standard strains of E. coli ATCC 25922 and Acinetobacter baumannii ATCC 19606 were used as negative control and positive control, respectively (14). Minimal inhibitory concentrations (MICs) for cefepime and ceftazidime were determined using the serial dilution method according to CLSI guidelines (15). Combined disk 
test (CDT) was performed on Mueller-Hinton agar plates (Merck, Germany) to evaluate production of ESBLs. Isolated strains were screened for susceptibility to a panel of four antibiotic discs viz: ceftazidime, cefotaxime, ceftazidime + clavulanic acid and cefotaxime + clavulanic acid. After 24 hours of incubation at $37{ }^{\circ} \mathrm{C}$, growth inhibition zone around the disk containing a combination of ceftazidime/cefotaxime and clavulanic acid was compared with the zone around the disk containing ceftazidime/cefotaxime alone. Inhibition zone diameter of $>5 \mathrm{~mm}$ or $50 \%$ (according to the manufacturer's guidelines) indicated ESBL production $(15,16)$.

Genomic DNA of the isolates was extracted by boiling method. The PER and VEB ESBL genes were amplified using universal primers (CinnaGene, Iran) (Table 1) (17).

The PCR reaction was performed in a final volume of $25 \mu \mathrm{L}$ containing $9 \mu \mathrm{L}$ Master Mix (2x) (Amplicon III of Denmark), 15-20 ng/ $\mu \mathrm{L}$ of DNA template, 10 pmol of each primer and double-distilled water to volume the solution. Thermal programs used for amplification of the PER gene was as follows: initial denaturation at $94{ }^{\circ} \mathrm{C}$ for 4 minutes, denaturation at $94{ }^{\circ} \mathrm{C}$ for 1 minute, annealing at $55{ }^{\circ} \mathrm{C}$ for 1 minute, extension at $72{ }^{\circ} \mathrm{C}$ for 1 minute and final extension at $72{ }^{\circ} \mathrm{C}$ for 5 minutes. Thermal program for amplification of the $V E B$ gene was as follows: initial denaturation at $94{ }^{\circ} \mathrm{C}$ for 5 minutes, denaturation at $94{ }^{\circ} \mathrm{C}$ for 1 minute, annealing at $53{ }^{\circ} \mathrm{C}$ for 1 minute, extension at $72{ }^{\circ} \mathrm{C}$ for 1 minute and final extension at $72{ }^{\circ} \mathrm{C}$ for 5 minutes. The PCR products were subjected to direct double-stranded DNA sequencing (PCR Thermocycler, America).

A 100 bp DNA ladder (PR901644, CinnaGene, Iran) was used as molecular marker for size of the amplicons. The amplified bands were visualized and photographed under UV ligh.

Table 1- The sequence of primers, annealing temperatures and expected PCR product sizes

\begin{tabular}{|c|c|c|c|}
\hline Primer & Primer sequences & $\begin{array}{c}\text { Annealing } \\
\text { temperature }\end{array}$ & Product size (bp) \\
\hline VEB-F & 5'-GAAACAACTTTGACGATTGA-3' & $52{ }^{\circ} \mathrm{C}$ & 370 \\
\hline VEB-R & 5'-СCCTGTTTTATGAGCAACAA-3' & & \\
\hline PER-F & 5'-ATGAATGTCATTATAAAAGC-3' & $48^{\circ} \mathrm{C}$ & 925 \\
\hline PER-R & 5'-AATTTGGGCTTAGGGCAGAA-3' & & \\
\hline
\end{tabular}

\section{RESULTS}

Among the 100 clinical samples, 50 isolates were identified as Acinetobacter species. In addition, 36 samples $(72 \%)$ were identified as A. baumannii, nine samples $(18 \%)$ as A. lwoffii and five samples (10\%) as other Acinetobacter species. All A. baumannii strains were resistant to cefixime, ceftriaxone and cefepime. The lowest rate of resistance was observed against polymyxin B (11\%).
Moreover, $18 \%$ of A. baumannii isolates were only resistant to one antibiotic. Furthermore, $12 \%$ of the A. baumannii isolates were resistant to two antibiotics, while $70 \%$ of the isolates were resistant to three or more (Table $2)$. The MIC against ceftazidime and cefepime was $<128 \mu \mathrm{g} / \mathrm{ml}$ in $84 \%$ and $91 \%$ of strains, respectively. According to the results of CDT, $21 \%$ of the strains produced ESBL (Figure 1).

Table 2- Antibiotic resistance patterns of $A$. baumannii isolates

\begin{tabular}{|c|c|c|c|c|c|}
\hline Antibiotic & abbreviation & Resistance (\%) & Antibiotic & Abbreviation & Resistance (\%) \\
\hline Cefpodoxime & CPD & 98 & Co-Trimixazole & BA & 75 \\
\hline Ceftizoxime & $\mathbf{C L}$ & 92 & Gentamicin & GM & 78 \\
\hline Cefixime & CFM & 100 & Ciprofloxacin & CIP & 80 \\
\hline Ticarcilin & TC & 85 & Levofloxacin & LVX & 84 \\
\hline Aztreonam & ATM & 95 & Meropenem & MEM & 91 \\
\hline Ceftriaxone & CRO & 100 & Imipenem & IPM & 94 \\
\hline Ceftazidime & $\mathrm{CAZ}$ & 97 & Ampicillin-sulbactam & AS & 45 \\
\hline Amikacin & AK & 92 & Colisitin & $\mathrm{CO}$ & 16 \\
\hline Cefepime & FEP & 100 & Polymyxin B & PB & 11 \\
\hline
\end{tabular}


Results of PCR showed that $32 \%$ and $47 \%$ of the isolates contained the $V E B$ and $P E R$ resistance genes, respectively (Figures 2 and
3). Results of sequencing for $V E B$ and $P E R$ were reported as Veb:kx349205 and Per:kx349204, respectively.

Figure 1- Inhibition zone diameter of $A$. baumannii isolates in the CDT method

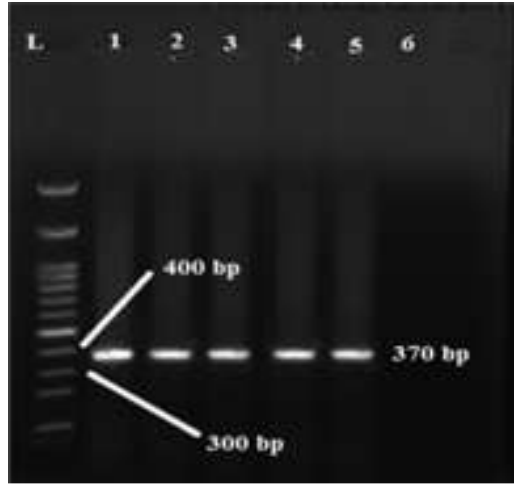

Figure 2- PCR amplification of the bla_VEB gene. Column L: 100 bp marker; column 1: positive control;

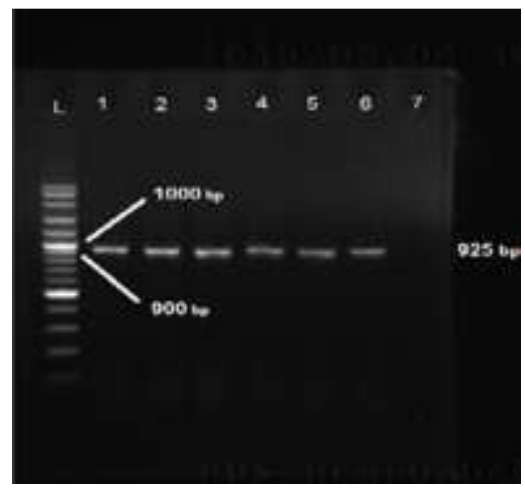

\section{DISCUSSION}

A. baumannii is an opportunistic pathogen and one of the main causes of nosocomial infections. Treatment is difficult, especially in the case of multi-drug resistant and ESBL-producing strains. In the past 30 years, several new $\beta$-lactam antibiotics have been produced that are resistant to $\beta$ lactamases. Nowadays, the prevalence of drug resistance is increasing due to inactivation of a wide range of $\beta$-lactam antibiotics, especially third-generation cephalosporins and aztreonams. This has created numerous problems in the treatment of microbial infections.

In this study, $72 \%$ of Acinetobacter isolates were identified as A. baumannii. The rest were A. Iwoffii and other Acinetobacter species. These results are similar to study of Constantinou et al. which reported that $71.5 \%$ and $29 \%$ of isolates were A. baumannii and $A$. lwoffii, respectively (18). Ritand et al. also reported that among 4180 clinical isolates, $74.02 \%$ were A. baumannii and the rest were A. lwoffii and other Acinetobacter species (19).
The rate of antibiotic resistance for most isolates is in agreement with the results obtained by Perez et al. and Begum et al. (20, 21) Similar to studies of Daly et al. (22) and Kamalbeik et al. (23), we found that most isolates were resistant to ceftazidime and cefepime. We also found that $84 \%$ of the strains had MIC of $<128 \mu \mathrm{g} / \mathrm{ml}$ for ceftazidime, while study of Shahcheraghi et al. (24) reported that $83.1 \%$ of isolates had MIC of $>64 \mu \mathrm{g} / \mathrm{ml}$. Regarding the MIC value for ceftazidime, our results are similar to the results of some studies conducted in Korea and Taiwan (25). In this study, $23 \%$ of $A$. baumannii strains produced ESBL. This findings is in line with findings of Sinha et al. (26) and Shahcheraghi et al. (24) .

We also found that $47 \%$ of $A$. baumannii isolates contained the PER gene. However, studies conducted by Kim et al. (27) and Farajnia et al. (28) reported the frequency of PER gene as $78.6 \%$ and $51 \%$, respectively. In the present study, frequency of the $V E B$ gene was $32 \%$ in A. baumannii isolates. Different 
results have been reported in studies conducted by Farajnia et al. (10\%) (28), Pasteran et al. (47.61\%) (29) and Poirel et al. (66\%) (30). This difference could be due to the type of samples and antibiotic disk, concentration of antibiotics, geographical location and test conditions.

\section{CONCLUSION}

The increased resistance to expandedspectrum cephalosporins is of great clinical importance, especially for hospitalized patients. Identification of patients infected

\section{REFERENCES}

1. Wallace L, Daugherty SC, Nagaraj S, Johnson JK, Harris AD, Rasko DA. Use of Comparative Genomics To Characterize the Diversity of Acinetobacter baumannii Surveillance Isolates in a Health Care Institution. Antimicrobial Agents and Chemotherapy. 2016; 60(10): 5933-41. doi: 10.1128/AAC.00477-16.

2. Wang H, Guo P, Sun H, Wang H, Yang Q, Chen M, et al. Molecular epidemiology of clinical isolates of carbapenem-resistant Acinetobacter spp. from Chinese hospitals. Antimicrobial Agents and Chemotherapy. 2007; 51(11): 4022-8.

3. Murray PR, Baron EJ, Jorgensen J, Landry M, Pfaller M. Manual of clinical microbiology. ASM Press: Washington,DC. 2006(Ed. 9):1-1267.

4. Bou G, Oliver A, Martínez-Beltrán J. OXA-24, a novel class $D$ B-lactamase with carbapenemase activity in an Acinetobacter baumanniiclinical strain. Antimicrobial Agents and Chemotherapy. 2000; 44(6): 1556-61.

5. Fagon J-Y, Chastre J, Domart Y, Trouillet J-L, Gibert C. Mortality due to ventilator-associated pneumonia or colonization with Pseudomonas or Acinetobacter species: assessment by quantitative culture of samples obtained by a protected specimen brush. Clinical infectious diseases. 1996; 23(3): 538-42.

6. Gastmeier P, Schwab F, Bärwolff S, Rüden H, Grundmann H. Correlation between the genetic diversity of nosocomial pathogens and their survival time in intensive care units. Journal of Hospital Infection. 2006;62(2):181-6. DOI:10.1016/j.jhin.2005.08.010.

7. Coia J, Duckworth G, Edwards D, Farrington M, Fry $\mathrm{C}$, Humphreys $\mathrm{H}$, et al. Guidelines for the control and prevention of meticillin-resistant Staphylococcus aureus (MRSA) in healthcare facilities. Journal of Hospital Infection. 2006; 63 (Suppl 1): S1-44.

8. Landman D, Quale JM, Mayorga D, Adedeji A, Vangala K, Ravishankar J, et al. Citywide clonal outbreak of multiresistant Acinetobacter baumannii and Pseudomonas aeruginosa in Brooklyn, NY: the preantibiotic era has returned. Archives of internal medicine. 2002; 162(13): 1515-20.

9. Carmeli Y, Troillet N, Eliopoulos GM, Samore MH. Emergence of antibiotic-resistant Pseudomonas aeruginosa: comparison of risks associated with different antipseudomonal agents. Antimicrobial Agents and Chemotherapy. 1999; 43(6): 1379-82. with ESBL-producing bacteria, appropriate selection of antibiotics, identification of $\beta$ lactamase-producing strains and preventing the spread of resistant bacteria in hospitals could help eliminate this problem.

\section{ACKNOWLEDGMENTS}

The authors would like to thank the Islamic Azad University of Qom for supporting this project.

\section{CONFLICT OF INTEREST}

There is no conflict of interest.

10. Thirapanmethee K. Extended spectrum $\beta$-lactamases: critical tools of bacterial resistance. Mahidol Univ $\mathbf{J}$ Pharm Sci. 2012; 39(1): 1-8.

11. Naas T, Poirel L, Nordmann P. Minor extendedspectrum $\beta$-lactamases. Clinical microbiology and infection. 2008; 14(1): 42-52.

12. Bali EB, Accedil L, Sultan N. Phenotypic and molecular characterization of SHV, TEM, CTX-M and extended-spectrum-lactamase produced by Escherichia coli, Acinobacter baumannii and Klebsiella isolates in a Turkish hospital. African Journal of Microbiology Research. 2010; 4(8): 650-4.

13. Baygloo NS, Bouzari M, Rahimi F, Abedini F, Yadegari S, Soroushnia $\mathrm{M}$, et al. Identification of Genomic Species of Acinetobacter Isolated from Burns of ICU Patients. Archives of Iranian Medicine (AIM). 2015; 18(10):638-42. doi: 0151810/AIM.005.

14. Wayne P. Performance standards for antimicrobial susceptibility testing:Twenty-second informational supplement. CLSI document M100-S22. Clinical Laboratory Standards institue. 2012; 32(3): 1-126.

15. Swenson JM, Killgore GE, Tenover FC. Antimicrobial susceptibility testing of Acinetobacter spp. by NCCLS broth microdilution and disk diffusion methods. Journal of clinical microbiology. 2004; 42(11): 5102-8. DOI:10.1128/JCM.42.11.5102-5108.2004.

16. Shakibaie MR, Adeli S, Salehi MH. Antibiotic resistance patterns and extended-spectrum $\beta$-lactamase production among Acinetobacter spp. isolated from an intensive care Unit of a hospital in Kerman, Iran. Antimicrobial resistance and infection control. 2012;1(1):1. doi: 10.1186/2047-2994-1-1.

17. Alikhani MY, Tabar ZK, Mihani F, Kalantar E, Karami P, Sadeghi M, et al. Antimicrobial resistance patterns and prevalence of blaPER-1 and blaVEB-1 genes among ESBL-producing Pseudomonas aeruginosa isolates in West of Iran. Jundishapur Journal of Microbiology. 2014; 7(1): e8888. doi: 10.5812/jjm.8888.

18. Constantiniu S, Romaniuc A, Chiriac R, Berea C, Kalis O, Rezus E, et al. Antibacterial antibodies for some enterobacteria in sera of patients with reactive arthritis and other rheumatoid diseases. Roum Arch Microbiol Immunol. 2008; 67(1-2): 30-5. 
19. Rit K, Saha R. Multidrug-resistant acinetobacter infection and their susceptibility patterns in a tertiary care hospital. Nigerian Medical Journal. 2012; 53(3): 126-8. doi: 10.4103/0300-1652.104379.

20. Perez F, Hujer AM, Hujer KM, Decker BK, Rather PN, Bonomo RA. Global challenge of multidrugresistant Acinetobacter baumannii. Antimicrobial Agents and Chemotherapy. 2007;51(10):3471-84 DOI:10.1128/AAC.01464-06.

21. Begum S, Hasan F, Hussain S, Shah AA. Prevalence of multi drug resistant Acinetobacter baumannii in the clinical samples from Tertiary Care Hospital in Islamabad, Pakistan. Pakistan journal of medical sciences. 2013; 29(5): 1253-1258.

22. Dally S, Lemuth K, Kaase M, Rupp S, Knabbe C, Weile J. DNA microarray for genotyping antibiotic resistance determinants in Acinetobacter baumannii clinical isolates. Antimicrobial Agents and Chemotherapy. 2013; 57(10): 4761-8. doi: 10.1128/AAC.00863-13.

23. Kamalbeik S, Talaie H, Mahdavinejad A, Karimi A, Salimi A. Multidrug-resistant Acinetobacter baumannii infection in intensive care unit patients in a hospital with building construction: is there an association? Korean journal of anesthesiology. 2014; 66(4): 295-9. doi: $10.4097 / \mathrm{kjae} .2014 .66 .4 .295$.

24. Shahcheraghi F, Abbasalipour M, Feizabadi M, Ebrahimipour G, Akbari N. Isolation and genetic characterization of metallo- $\beta$-lactamase and carbapenamase producing strains of Acinetobacter baumannii from patients at Tehran hospitals. Iranian journal of microbiology. 2011; 3(2): 68-74.
25. Lee K, Yong D, Jeong SH, Chong Y. MultidrugResistant Acinetobacter spp.: Increasingly Problematic Nosocomial Pathogens. Yonsei Med J. 2011; 25(6): 87991. doi: 10.3349/ymj.2011.52.6.879.

26. Sinha M, Srinivasa H, Macaden R. Antibiotic resistance profile \& extended spectrum beta-lactamase $(E S B L)$ production in Acinetobacter species. Indian journal of medical research. 2007; 126(1): 63-7.

27. Kim J, Heo S, Jin J, Choi C, Lee Y, Jeong Y, et al. Characterization of Acinetobacter baumannii carrying blaOXA-23, blaPER-1 and armA in a Korean hospital. Clinical microbiology and infection. 2008; 14(7): 716-8.

28. Farajnia S, Azhari F, Alikhani MY, Hosseini MK, Peymani A, Sohrabi N. Prevalence of PER and VEB type extended spectrum betalactamases among multidrug resistant Acinetobacter baumannii isolates in North-West of Iran. Iranian journal of basic medical sciences. 2013; 16(6): $751-5$

29. Pasterán F, Rapoport M, Petroni A, Faccone D, Corso A, Galas M, et al. Emergence of PER-2 and VEBla in Acinetobacter baumannii strains in the Americas. Antimicrobial Agents and Chemotherapy. 2006; 50(9): 3222-4. doi: 10.1128/AAC.00284-06.

30. Poirel L, Corvec S, Rapoport M, Mugnier P, Petroni $\mathrm{A}$, Pasteran F, et al. Identification of the novel narrowspectrum $\beta$-lactamase SCO-1 in Acinetobacter spp. from Argentina. Antimicrobial Agents and Chemotherapy. 2007; 51(6): 2179-84. doi: 10.1128/AAC.01600-06. 